\title{
Public Health Threat Assessment of Vehicular Load Index-Induced Urban Air Pollution Indices Near Traffic Intersections In Central India
}

\author{
Raghvendra Gumashta ${ }^{1}$, Aanchal Bijlwan ${ }^{1}$ \\ 1. Community Medicine, People's College of Medical Sciences and Research Centre, Bhopal, IND
}

Corresponding author: Aanchal Bijlwan, aanchalbijlwan.ab@gmail.com

\begin{abstract}
Objectives: To assess traffic vehicular load, levels of various air pollutants, their correlation at selected traffic intersections of Bhopal city and to suggest suitable public health measures.

Methods: A transverse study was conducted by convenience sampling with equated distribution among vehicular load-based large (Group1:G1: $10 \mathrm{TI}$ ), medium (Group2:G2: 5 TI), and small (Group3:G3: 5 TI) traffic-intersections (TI) through a systematic stratified random selection of study sites to assess traffic vehicle load index (VLI).
\end{abstract}

Results: VLI,G1 (cumulative mean: 16.31; day-time (DT): 19.03, DT range 11.68-51.49; night-time (NT): 13.59, NT range 11.7-18.0), VLI,G2 (cumulative mean: 0.965; DT:0.971, DT range 08.56-11.67; NT: 0.960, NT range 07.54-11.39), and VLI,G3 (cumulative mean: 06.17; DT:06.08, DT range 04.12-06.86; NT: 06.27, NT range 03.74-07.53). There is a significant intergroup difference of the mean (G1 vs G2: $p=0.03)$; (G1 vs G3: $\mathrm{p}=0.002$ ); (G2 vs G3: $\mathrm{p}=0.003$ ). The range of VLI is found to be wide within G1 (DT; 11.68-51.49; NT 11.718.00) as compared to narrow range in G2 (DT; 8.56-11.67; NT7.54-11.39) and G3 (DT; 4.12-6.86; NT 3.74$7.53)$.

Conclusion: High air pollution noted at TIs and associated exposure to unprotected commuters pose publichealth risks. It has long-term health consequences requiring focused multidisciplinary preventive interventions.

Review began 10/10/2020 Review ended 10/15/2020 Published 10/24/2020

\section{(c) Copyright 2020}

Gumashta et al. This is an open access article distributed under the terms of the Creative Commons Attribution License CC-BY 4.0, which permits unrestricted use, distribution, and reproduction in any medium, provided the original author and source are credited.
Categories: Preventive Medicine, Public Health, Other

Keywords: air pollution, assessment, particulate matter, public health, traffic

\section{Introduction}

Air pollution has been posing long-term, medium-term, and short-term challenges since long to the public health authorities thereby adversely affecting air quality indices [1]. PM10 standards for the ecologically sensitive area as per National Ambient Air Quality Standards is $60 \mu \mathrm{g} / \mathrm{m}^{3}$ for an annual time-weighted mean of a minimum 104 measurements in a year at a particular site taken twice a week, 24 hourly at uniform intervals. PM10 standards for 24 hours time-weighted mean is $100 \mu \mathrm{g} / \mathrm{m}^{3}$. There is a felt need to revise PM10 standards to ensure avoidance of air pollution through preventive interventions at multiple levels with a special focus on maternal and child health [2].

Many studies have conducted air pollution indices in an indoor environment, but the studies related to the outdoor environment are much needed [3-8]. In 2015, Government of India, together with IIT Kanpur launched the National Air Quality Index. In 2019, India launched "The National Clean Air Programme" with a tentative national target of 20-30\% reduction in PM2.5 and PM10 concentrations by 2024, considering 2017 as the base year for comparison. It will be rolled out in 102 cities that are considered to have air quality worse than the National Ambient Air Quality Standards. The present study will identify the traffic load wise pollution indices and their interrelationship. Hence, this study shall enrich the understanding of the vehicular pollution load in Central India as per the important pollution indicators.

We hypothesize that the analysis of various pollutants viz. (PM 2.5, TVOC, $\mathrm{CO}_{2}$, HCHO, PM1.0, PM 5.0, PM 10 , and submicron particles) influence outdoor air quality. These pollutants are a threat for enhanced health risks especially for the vulnerable population including the elderly, children, and pregnant women. Therefore, the purpose of this study is to assess traffic vehicular load, levels of various air pollutants, and their correlation at selected TIs of Bhopal city and to suggest suitable public health measures. This study will also provide recent most air pollution scenario in moderately populated Bhopal city for possible timely preventive interventions.

\section{Materials And Methods}




\section{Cureus}

A transversal study was conducted at a Tertiary Health Care Centre, Bhopal, India from June to September, 2019 to assess traffic vehicular load, levels of various air pollutants and their correlation at selected TIs of Bhopal city, and to suggest suitable public health measures.

\section{Sample collection}

The systematic stratified random selection of the TIs was conducted by convenience sampling with equated distribution among load-based large (Group1-G1), medium (Group2-G2), and small (Group3-G3) TIs (total 20). Vehicle load index (VLI) was assessed using "vehicular indices calculation matrix datasets." The vehicle load was determined herein by the exclusive VLI developed in this study assuming the load of each twowheeler, three-wheeler, cars, medium vehicle, and the heavy vehicle being 1.0, 1.5, 2.0, 2.0, and 6.0, respectively. The number of vehicles passing through each studied TIs was assessed lane wise as a mean of three readings at day-time (DT) and night-time (NT) for three days inclusive of last day being the reading date for all the air pollutants using calibrated Ambee Air Quality Monitor TM. The total number of TIs ( $\mathrm{n}=20)$ included in the study were distributed in high traffic areas (G1: $n=10)$, medium traffic area $(G 2: n=05)$, and low traffic area (G3: n=05). These included signaled (S) TIs (G1:07; G2:05; G3:01), semi-signaled (SS) TIs (G1:01; G3:01), non-signaled (NS) TIs (G1:02; G3:03S) (Tables 1 and 2). 


\section{Cureus}

\begin{tabular}{|c|c|c|c|c|c|c|c|}
\hline \multirow{2}{*}{ S.No. } & \multirow{2}{*}{ TI sites (S/SS/NS) \# } & \multicolumn{2}{|l|}{ VLI } & \multirow{2}{*}{ TI site mean } & \multicolumn{3}{|c|}{ TI group mean } \\
\hline & & DT & NT & & DT & NT & Overall mean \\
\hline 1 & Arera colony (S) & 51.49 & 18.00 & 34.74 & \multirow{11}{*}{19.03} & \multirow{11}{*}{13.59} & \multirow{11}{*}{16.31} \\
\hline 2 & Chetak bridge (S) & 19.76 & 17.23 & 18.49 & & & \\
\hline 3 & New market (S) & 18.83 & 13.97 & 16.4 & & & \\
\hline 4 & Shivaji nagar (S) & 16.94 & 13.34 & 15.14 & & & \\
\hline 5 & Anand nagar (NS) & 15.53 & 12.67 & 14.1 & & & \\
\hline 6 & Old city (NS) & 15.01 & 12.48 & 13.7 & & & \\
\hline 7 & Ambedkar Square (S) & 14.52 & 12.3 & 13.4 & & & \\
\hline 8 & Lalghati (S) & 14.24 & 12.28 & 13.26 & & & \\
\hline 9 & Piplani (SS) & 12.34 & 11.94 & 12.14 & & & \\
\hline 10 & Polytech (S) & 11.68 & 11.7 & 11.69 & & & \\
\hline \multicolumn{5}{|c|}{ G2: Total 05 TIs: Medium traffic areas } & & & \\
\hline 11 & Bus st. (S) & 11.67 & 11.39 & 11.53 & \multirow{5}{*}{09.71} & \multirow{5}{*}{09.60} & \multirow{5}{*}{09.65} \\
\hline 12 & Karond (S) & 09.98 & 10.1 & 10.04 & & & \\
\hline 13 & Chowk (S) & 09.29 & 09.69 & 09.54 & & & \\
\hline 14 & Habibganj (S) & 09.07 & 09.31 & 08.155 & & & \\
\hline 15 & Railway station (S) & 08.56 & 07.54 & 08.05 & & & \\
\hline \multicolumn{8}{|c|}{ G3: Total 05 TIs: low traffic areas } \\
\hline 16 & Gandhi nagar (S) & 06.86 & 07.53 & 07.19 & \multirow{5}{*}{06.08} & \multirow{5}{*}{06.27} & \multirow{5}{*}{06.17} \\
\hline 17 & Mandi (SS) & 06.83 & 06.88 & 06.85 & & & \\
\hline 18 & Narela (NS) & 06.55 & 06.83 & 06.69 & & & \\
\hline 19 & Ayodhya (NS) & 06.07 & 06.38 & 06.22 & & & \\
\hline 20 & Kasturba (NS) & 04.12 & 03.74 & 03.93 & & & \\
\hline
\end{tabular}

TABLE 1: VLI in the DT and NT at Tls of groups G1, G2, G3 in Bhopal city during June-September, 2019 ( $n=20)$

$\#(\mathrm{~S})=$ signaled $\mathrm{TI}$ : (NS)=non-signaled TI: (SS)= semi-signaled $\mathrm{TI}$.

TI: traffic intersection, VLI: vehicle load index, DT: daytime, NT: nighttime. 


\section{Cureus}

\begin{tabular}{|c|c|c|c|c|c|c|c|c|c|c|c|}
\hline \multirow{2}{*}{ Groups } & \multicolumn{2}{|l|}{ VLI } & \multicolumn{2}{|l|}{ TVOC } & \multicolumn{2}{|l|}{$\mathrm{CO}_{2}$} & \multicolumn{2}{|l|}{ HCHO } & \multicolumn{2}{|l|}{ PM10 } & \multirow{2}{*}{$\begin{array}{l}\text { Submicron particles }(>0.25,>0.3,>0.5,>10) \\
\text { present at (no. of } \mathrm{Tl} / \text { total } \mathrm{TI} \text { ) }\end{array}$} \\
\hline & ratio & mean & ratio & mean & ratio & mean & ratio & mean & ratio & mean & \\
\hline G1 & 1.40 & 16.31 & 2.45 & 0.73 & 1.30 & 1170.75 & 2.69 & 1.91 & 2.50 & 320.03 & $47 / 50$ \\
\hline G2 & 1.01 & 9.65 & 0.52 & 1.40 & 1.19 & 921.90 & 0.75 & 0.14 & 0.09 & 43.44 & $24 / 25$ \\
\hline G3 & 0.96 & 6.17 & 3.66 & 0.16 & 1.18 & 830.30 & 3.00 & 0.02 & 0.53 & 145.97 & $23 / 25$ \\
\hline
\end{tabular}

TABLE 2: Group-wise comparison of VLI with gaseous particles and particulate matter $(n=20)$

TI: traffic intersections, VLI: vehicle load index, TVOC: vehicle load index, DT: daytime, NT: nighttime.

\section{Measurement of pollution parameters}

Various pollutants PM2.5, TVOC, $\mathrm{CO}_{2}$, HCHO, PM1.0, PM5.0, PM10, particle size $>0.3 \mu \mathrm{m},>1.0 \mu \mathrm{m},>2.5$ $\mu \mathrm{m},>5.0 \mu \mathrm{m},>10 \mu \mathrm{m}$, temperature, dew point, humidity, ultraviolet, and visibility were recorded in DT and NT at all selected TIs using calibrated Ambee Air Quality Monitor ${ }^{\mathrm{TM}}$ (Ambee Pvt., Ltd., Mumbai, IND). Hence, the study variables included particulate matter: PM (PM 2.5, PM10, PM1, PM5); gaseous pollutants $\left(\mathrm{CO}_{2}, \mathrm{HCHO}, \mathrm{TVOC}\right)$; submicron particles $(>0.25 \mu \mathrm{m},>0.3 \mu \mathrm{m},>0.5 \mu \mathrm{m},>10 \mu \mathrm{m})$. In addition to the above, the meteorological conditions prevailing on the days of data collection included temperature, humidity, dew, wind speed, air pressure, ultraviolet radiation, and visibility. The inclusion criteria for the study were randomly selected ten large, five medium, and five small traffic transactions. The convenient sampling was done twice a day for three consecutive days at each of the randomly selected sites. The list of these categories was prepared based on the pilot study undertaken for the overall load of traffic transactions at ten intersections of Bhopal distributed in all of its geographical zones. Those not listed in the randomly selected list of traffic transactions were excluded from the study. The portable digital device used for assessing various pollution parameters in the study was Ambee Air Quality Monitor ${ }^{\mathrm{TM}}$.

\section{Study sites}

Twenty TIs were chosen in Bhopal city as per inclusion and exclusion criteria. Based on the traffic load, these TIs were divided into large, medium, and small. Various atmospheric pollutants studied included PM 2.5, PM 10, $\mathrm{HCHO}, \mathrm{CO}_{2}$, etc., were monitored using Ambee Air Quality Monitor ${ }^{\mathrm{TM}}$. Vehicle at the intersections was further divided into two-wheeler, three-wheeler, cars, heavy, and medium vehicles. Traffic load at each lane of each of the TIs was calculated for three consecutive days with the last day being data collection day for meteorological and air pollution parameters as well. The VLI was assessed as described above. The study was carried out at DT from peak traffic hours of 10 AM to $12 \mathrm{PM}$ and at night from 6 PM to 8 PM. Random quick interviews were also conducted among pollution under control (PUC) check service provider, car service agencies, roadside tyre puncture repair shops, and traffic constables in each of these categories (G1, G2, G3).

\section{Statistical analysis}

All data entered were analyzed using SPSS (Statistical Package for Social Science) Version 20 (IBM Corp, Armonk, USA).

\section{Results}

\section{Cumulative values of VLI}

VLI,G1 (cumulative mean: 16.31; DT: 19.03, DT range 11.68-51.49; NT: 13.59, NT range 11.7-18.0), VLI,G2 (cumulative mean: 0.965; DT: 0.971, DT range 08.56-11.67; NT: 0.960, NT range 07.54-11.39), and VLI,G3 (cumulative mean: 06.17; DT: 06.08, DT range 04.12-06.86; NT: 06.27, NT range 03.74-07.53). The TI site mean for G1 ranged 11.69-34.74, whereas the same for G2 and G3 were 8.05-11.53 and 03.93-07.19, respectively (Table 1). There is significant intergroup difference of the mean (G1 vs G2: $\mathrm{p}=0.03$ ); (G1 vs G3: $\mathrm{p}=0.002$ ); (G2 vs G3: $\mathrm{p}=0.003$ ) (Table 3) The range of VLI is found to be wide within G1 (DT: 11.68-51.49; NT: 11.7-18.00) as compared to narrow range in G2 (DT: 8.56-11.67; NT: 7.54-11.39) and G3 (DT: 4.12-6.86; NT: 3.74-7.53). 


\section{Cureus}

\begin{tabular}{|c|c|c|c|c|c|}
\hline S. No. & Description & Group & Spearman correlation (rs) & p-value (two-tailed) & Significance \\
\hline \multirow{4}{*}{1} & \multirow{4}{*}{ VLI vs PM2.5 } & G1 & -0.46 & 0.17 & - \\
\hline & & G2 & -0.6 & 0.28 & - \\
\hline & & G3 & 0.21 & 0.73 & - \\
\hline & & $\mathrm{G} 1+\mathrm{G} 2+\mathrm{G} 3$ & -0.43 & 0.05 & + \\
\hline \multirow{4}{*}{2} & \multirow{4}{*}{ VLI vs PM10 } & G1 & 0.12 & 0.72 & - \\
\hline & & G2 & -0.8 & 0.1 & - \\
\hline & & G3 & 0.79 & 0.11 & - \\
\hline & & $\mathrm{G} 1+\mathrm{G} 2+\mathrm{G} 3$ & -0.14 & 0.55 & - \\
\hline \multirow{4}{*}{3} & \multirow{4}{*}{ PM2.5 vs PM10 } & G1 & 0.28 & 0.42 & - \\
\hline & & G2 & 0.9 & 0.03 & + \\
\hline & & G3 & 0.4 & 0.5 & - \\
\hline & & G1+G2+G3 & 0.49 & 0.02 & + \\
\hline \multirow{4}{*}{4} & \multirow{4}{*}{ PM1.0 vs PM10 } & G1 & 0.87 & 0.00 & + \\
\hline & & G2 & 0.8 & 0.1 & - \\
\hline & & G3 & 0.5 & 0.39 & - \\
\hline & & $\mathrm{G} 1+\mathrm{G} 2+\mathrm{G} 3$ & 0.71 & 0.00 & + \\
\hline \multirow{4}{*}{5} & \multirow{4}{*}{ PM1.0 vs PM2.5 } & G1 & 0.53 & 0.1 & - \\
\hline & & G2 & 0.9 & 0.03 & + \\
\hline & & G3 & 0.6 & 0.28 & - \\
\hline & & $\mathrm{G} 1+\mathrm{G} 2+\mathrm{G} 3$ & 0.59 & 0.01 & + \\
\hline \multirow{4}{*}{6} & \multirow{4}{*}{ PM10 vs TVOC } & G1 & -0.04 & 0.9 & - \\
\hline & & G2 & 0.1 & 0.87 & - \\
\hline & & G3 & -0.35 & 0.55 & - \\
\hline & & $\mathrm{G} 1+\mathrm{G} 2+\mathrm{G} 3$ & -0.25 & 0.27 & - \\
\hline \multirow{4}{*}{7} & \multirow{4}{*}{$\mathrm{PM} 10$ vs $\mathrm{CO}_{2}$} & G1 & 0.21 & 0.55 & - \\
\hline & & G2 & 0.1 & 0.87 & - \\
\hline & & G3 & 0.1 & 0.87 & - \\
\hline & & $\mathrm{G} 1+\mathrm{G} 2+\mathrm{G} 3$ & 0.33 & 0.15 & - \\
\hline \multirow{4}{*}{8} & \multirow{4}{*}{ PM10 vs $\mathrm{HCHO}$} & G1 & 0.5 & 0.13 & - \\
\hline & & G2 & -0.66 & 0.21 & - \\
\hline & & G3 & -0.22 & 0.71 & - \\
\hline & & $\mathrm{G} 1+\mathrm{G} 2+\mathrm{G} 3$ & 0.05 & 0.82 & - \\
\hline
\end{tabular}

TABLE 3: Intragroup and intergroup Spearman's correlation coefficient for the observed noticeable values of importance (PM10, PM2.5, PM1, TVOC, CO2, HCHO, and VLI)

$(-)=$ not significant; $(+)=$ significant.

TVOC: total volatile organic compounds, PM: particulate matter, VLI: vehicle load index. 


\section{Cureus}

\section{Measuring air pollution indices}

The air pollution indices measured at DT and NT included gaseous particles (TVOC, $\mathrm{CO}_{2}, \mathrm{HCHO}$ ) particulate matter (PM1.0, PM2.5, PM5, PM10) and submicron particles ( $>0.3 \mu \mathrm{m},>1.0 \mu \mathrm{m},>2.5 \mu \mathrm{m},>5.0 \mu \mathrm{m},>10 \mu \mathrm{m})$ at all 10, 05, and 05 TIs of G1, G2, and G3, respectively. The group-wise range of values for air pollution indices are indicated for DT and NT pollution level (Tables 4 and 5).

\begin{tabular}{|c|c|c|c|c|c|c|c|c|c|c|c|c|c|c|}
\hline No. & TIs & VLI & $\begin{array}{l}\mathrm{PM} \\
2.5\end{array}$ & TVOC & $\mathrm{CO}_{2}$ & НСНО & $\begin{array}{l}\mathrm{PM} \\
1.0\end{array}$ & PM 5.0 & PM 10 & $\begin{array}{l}>0.3 \\
\mu \mathrm{m}\end{array}$ & $\begin{array}{l}>1.0 \\
\mu \mathrm{m}\end{array}$ & $\begin{array}{l}>2.5 \\
\mu \mathrm{m}\end{array}$ & $\begin{array}{l}>5.0 \\
\mu \mathrm{m}\end{array}$ & $\begin{array}{l}>10 \\
\mu \mathrm{m}\end{array}$ \\
\hline 1 & Arera colony & 51.49 & 26.1 & 1.02 & 1121 & 16.7 & 31 & 38.2 & 2720 & 320 & 112 & 30 & 10 & 3 \\
\hline 2 & Chetak bridge & 19.76 & 7.1 & 1.06 & 4043 & 0.15 & 3.77 & 8.15 & 8.3 & 710 & 198 & 19 & 6 & 2 \\
\hline 3 & New market & 18.83 & 1.35 & 0.17 & 1182 & 9.81 & 17.4 & 18.2 & 1617 & 189 & 56 & 18 & 7 & 5 \\
\hline 4 & Shivaji nagar & 16.94 & 21.12 & 1.61 & 627 & 0.23 & 0.97 & 1.25 & 2.09 & 24 & 9 & 0 & 0 & 0 \\
\hline 5 & Anand nagar & 15.53 & 41.6 & 0.09 & 996 & 0.01 & 18.8 & 45.1 & 45 & 2720 & 540 & 175 & 56 & 28 \\
\hline 6 & Old city & 15.01 & 0.48 & 0.09 & 737 & 0.01 & 0.32 & 0.41 & 0.42 & 115 & 1 & 0 & 0 & 0 \\
\hline 7 & $\begin{array}{l}\text { Ambedkar } \\
\text { Square }\end{array}$ & 14.52 & 43 & 1.61 & 1346 & 0.23 & 37.5 & 80.3 & 87.9 & 6568 & 854 & 244 & 72 & 36 \\
\hline 8 & Lalghati & 14.24 & 63.3 & 0.16 & 568 & 0.02 & 12.5 & 37 & 31.7 & 4170 & 262 & 59 & 16 & 4 \\
\hline 9 & Piplani & 12.34 & 36.2 & 0.5 & 2047 & 0.07 & 16 & 36 & 35.3 & 2765 & 5512 & 144 & 51 & 19 \\
\hline 10 & Polytech & 11.68 & 30.8 & 4.08 & 578 & 0.58 & 10.8 & 25.6 & 28.9 & 2081 & 322 & 109 & 28 & 8 \\
\hline 11 & Bus stand & 11.67 & 40.8 & 0.42 & 767 & 0.06 & 37.4 & 53.6 & 54.3 & 6023 & 505 & 59 & 15 & 0 \\
\hline 12 & Karond & 9.98 & 26.1 & 0.42 & 2555 & 0.06 & 12.5 & 37.6 & 44.5 & 2207 & 497 & 209 & 61 & 38 \\
\hline 13 & Chowk & 9.29 & 21.3 & 1.34 & 714 & 0.1 & 0.09 & 1.33 & 0.66 & 54.2 & 15 & 10 & 0 & 1 \\
\hline 14 & Habibganj & 9.07 & 0.11 & 2.53 & 946 & 0.36 & 0.14 & 0.38 & 0.4 & 38 & 4 & 2 & 0 & 0 \\
\hline 15 & Railway station & 8.56 & 27.4 & 0.22 & 648 & 0.03 & 16 & 21.9 & 21.5 & 2698 & 151 & 10 & 0 & 0 \\
\hline 16 & Gandhi nagar & 6.86 & 37.4 & 0.09 & 578 & 0.01 & 20.3 & 44.4 & 46.1 & 2970 & 599 & 1111 & 17 & 1 \\
\hline 17 & Mandi & 6.83 & 22.5 & 0.3 & 1225 & 0.04 & 14.6 & 46.4 & 50.3 & 3026 & 727 & 337 & 126 & 54 \\
\hline 18 & Narela & 6.55 & 32.3 & 0.09 & 727 & 0.01 & 154 & 35.9 & 37.7 & 2584 & 440 & 94 & 9 & 6 \\
\hline 19 & Ayodhya & 6.07 & 5.51 & 0.56 & 797 & 0.08 & 4.45 & 11 & 11.8 & 758 & 112 & 43 & 3 & 0 \\
\hline 20 & Kasturba & 4.12 & 30.2 & 0.1 & 878 & 0.01 & 0.06 & 17.8 & 32.3 & 140 & 327 & 109 & 16 & 0 \\
\hline
\end{tabular}

TABLE 4: Air pollution indices at DT (10 AM to 12 PM) during June-September, 2019 in Bhopal city $(n=20)$

TI: traffic intersection, TVOC: total volatile organic compounds, VLI: vehicle load index. 


\begin{tabular}{|c|c|c|c|c|c|c|c|c|c|c|c|c|c|c|}
\hline $\begin{array}{l}\text { S. } \\
\text { No. }\end{array}$ & Tls & VLI & $\begin{array}{l}\text { PM } \\
2.5\end{array}$ & TVOC & $\mathrm{CO}_{2}$ & $\mathrm{HCHO}$ & $\begin{array}{l}\text { PM } \\
1.0\end{array}$ & $\begin{array}{l}\text { PM } \\
5.0\end{array}$ & $\begin{array}{l}\mathrm{PM} \\
10\end{array}$ & $\begin{array}{l}>0.3 \\
\mu \mathrm{m}\end{array}$ & $\begin{array}{l}>1.0 \\
\mu \mathrm{m}\end{array}$ & $\begin{array}{l}>2.5 \\
\mu \mathrm{m}\end{array}$ & $\begin{array}{l}>5.0 \\
\mu \mathrm{m}\end{array}$ & $\begin{array}{l}>10 \\
\mu \mathrm{m}\end{array}$ \\
\hline 1 & Chetak bridge & 18 & 8.75 & 0.86 & 1651 & 0.12 & 6.57 & 10.5 & 10.7 & 1350 & 120 & 26 & 4 & 0 \\
\hline 2 & Anand nagar & 17.23 & 32.4 & 0.35 & 977 & 0.05 & 17 & 40.4 & 42.9 & 2790 & 520 & 133 & 39 & 15 \\
\hline 3 & Shivaji nagar & 13.97 & 12.3 & 1.35 & 1176 & 0.19 & 9.81 & 17.4 & 18.2 & 1617 & 189 & 56 & 10 & 2 \\
\hline 4 & New market & 13.34 & 1.35 & 0.19 & 1176 & 9.81 & 17.4 & 18.2 & 1617 & 189 & 56 & 18 & 7 & 0 \\
\hline 5 & Piplani & 12.67 & 72.9 & 0.79 & 1186 & 0.11 & 33.3 & 74.2 & 87.9 & 6637 & 940 & 374 & 141 & 53 \\
\hline 6 & Lalghati & 12.48 & 10.4 & 0.09 & 648 & 0.01 & 6.15 & 12.7 & 13.3 & 1080 & 165 & 37 & 11 & 9 \\
\hline 7 & $\begin{array}{l}\text { Ambedkar } \\
\text { square }\end{array}$ & 12.3 & 4.5 & 0.07 & 578 & 0.01 & 9.11 & 13.87 & 14.02 & 187 & 32 & 1 & 0 & 0 \\
\hline 8 & Old city & 12.28 & 37.2 & 0.04 & 865 & 0.02 & 3.71 & 5.1 & 0.33 & 108 & 1 & 0 & 0 & 0 \\
\hline 9 & Polytech & 11.94 & 2.96 & 0.09 & 568 & 0.01 & 0.74 & 1.24 & 1.25 & 200 & 12 & 0 & 0 & 0 \\
\hline 10 & Arera colony & 11.7 & 23.1 & 0.43 & 1345 & 0.06 & 10.5 & 17.9 & 18.5 & 1712 & 181 & 24 & 3 & 2 \\
\hline 11 & Karond & 11.39 & 39 & 0.07 & 638 & 0.01 & 8.84 & 20.2 & 43.7 & 1385 & 294 & 78 & 21 & 54 \\
\hline 12 & Bus stand & 10.1 & 27.8 & 6.11 & 875 & 0.54 & 22.5 & 28.9 & 43 & 1345 & 321 & 35 & 8 & 4 \\
\hline 13 & Habibganj & 9.69 & 14.3 & 0.42 & 1440 & 0.03 & 10.6 & 19.2 & 20.3 & 1990 & 212 & 58 & 10 & 2 \\
\hline 14 & Chowk & 9.31 & 19.38 & 2.41 & 738 & 0.21 & 0.11 & 1.03 & 1.01 & 57 & 11 & 14 & 10 & 0 \\
\hline 15 & Mandi & 7.54 & 28.9 & 0.27 & 1022 & 0.02 & 11.4 & 50.2 & 1151 & 642 & 449 & 126.4 & 42 & 12 \\
\hline 16 & Gandhi nagar & 7.53 & 28.3 & 0.05 & 607 & 0.01 & 30.2 & 247 & 58.7 & 1990 & 628 & 79 & 11 & 0 \\
\hline 17 & Railway station & 6.88 & 22.3 & 0.1 & 392 & 0.01 & 17 & 20 & 205 & 2440 & 134 & 11 & 1 & 0 \\
\hline 18 & Ayodhya & 6.83 & 12.1 & 0.1 & 732 & 0.01 & 7.9 & 8.9 & 7.2 & 1101 & 38 & 0 & 0 & 0 \\
\hline 19 & Narela & 6.38 & 29.9 & 0.01 & 805 & 0.01 & 11.4 & 28.9 & 40.4 & 977 & 374 & 71 & 11 & 2 \\
\hline 20 & Kasturba & 3.74 & 27.8 & 0.08 & 932 & 0.01 & 0.03 & 0.16 & 24.2 & 116 & 242 & 98 & 10 & 0 \\
\hline
\end{tabular}

TABLE 5: Air pollution indices at NT (6 PM to 8 PM) during June-September, 2019 in Bhopal city $(n=20)$

TI: traffic intersection, TVOC: total volatile organic compounds, VLI: vehicle load index.

Cumulative range values of gaseous particles, particulate matter, and submicron particles

The cumulative range values of DT and NT were also assessed (Table 5). The noticeably high-value levels among groups (G1, G2, G3) were found for the following parameters (as per observed TI/total TI: G1: TVOC 7/10; $\mathrm{CO}_{2}-8 / 10 ; \mathrm{HCHO}-6 / 10$; PM10 - 2/10, and submicron particles at all sites for all sizes ranging $>0.3 \mu \mathrm{m}$ to $>10 \mu \mathrm{m}$ except at 3/50 readings; $\mathrm{G} 2$ : TVOC $-3 / 5 ; \mathrm{CO}_{2}-4 / 5 ; \mathrm{HCHO}-3 / 5 ; \mathrm{PM} 10-1 / 5$, and submicron particles at all sites for all sizes ranging $>0.3 \mu \mathrm{m}$ to $>10 \mu \mathrm{m}$ except at $1 / 25$ readings; $\mathrm{G}_{3}: \mathrm{CO}_{2}-4 / 5$; PM10 $-1 / 5$ and submicron particles at all sites for all sizes ranging $>0.3 \mu \mathrm{m}$ to $>10 \mu \mathrm{m}$ except at $2 / 25$ readings). It is further observed from group-wise data that $\mathrm{CO}_{2}$ level is found increased in all the groups almost at all sites except $4 / 20$, whereas TVOC and HCHO are not found increased in G3. TVOC and HCHO are found generally raised in G1 and G2 with cumulative non-observance in 5/15 sites and 6/15 sites, respectively. The TIs with the market area have essentially shown PM10 to be high irrespective of group categorization of the concerned site (Table ๑). 


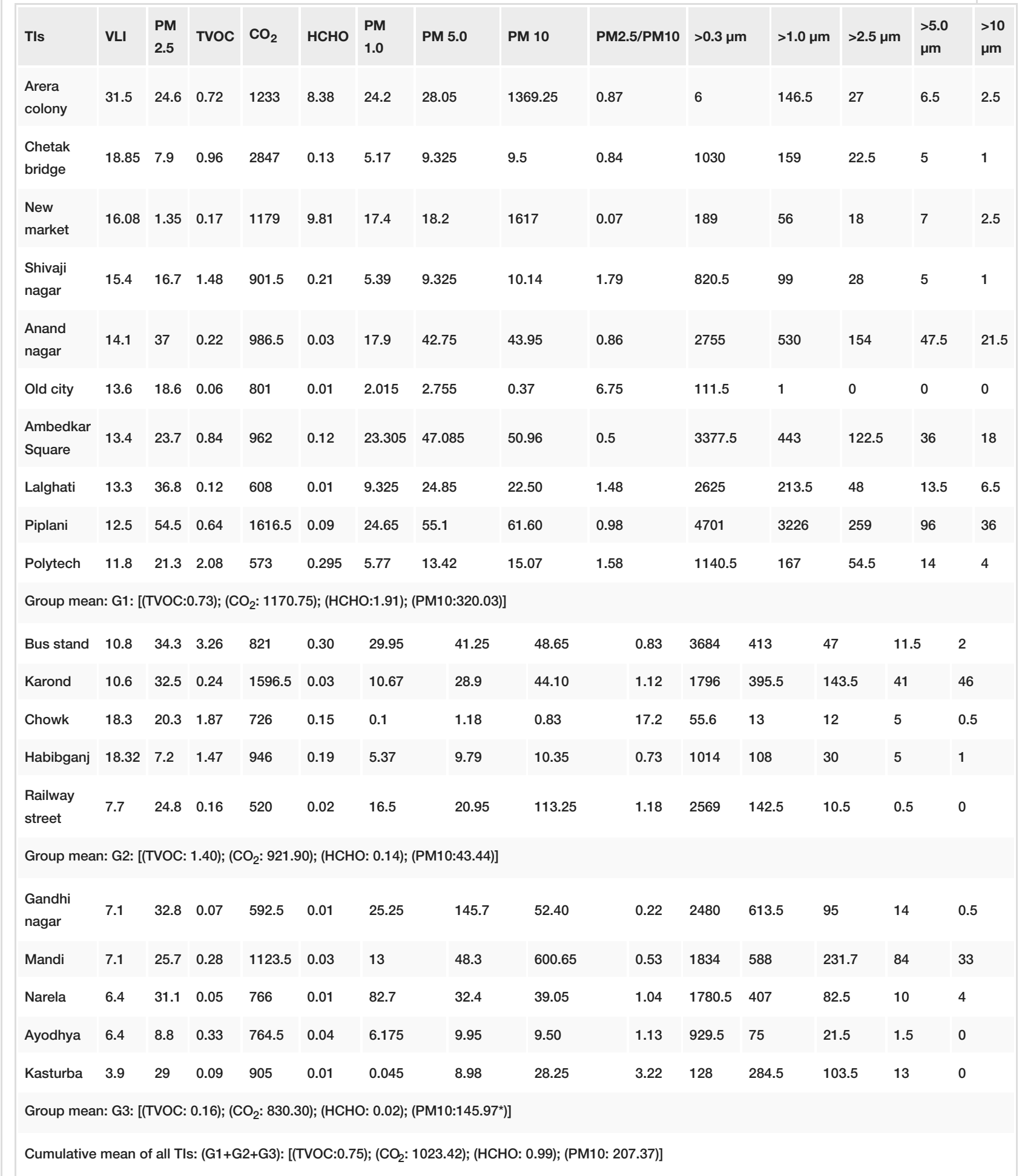

TABLE 6: Cumulative values of DT and NT gaseous particles, particulate matter, and submicron particles against observed vehicular load as assessed by VLI in Bhopal city during June-

September, 2019 ( $n=20)$

TI: traffic intersection, TVOC: total volatile organic compounds, VLI: vehicle load index.

TVOC (cumulative 0.75; range 0.05-3.26; G1: 0.73; G2: 1.40; G3: 0.16); $\mathrm{CO}_{2}$ (cumulative 1023.42; range 5202847; G1: 1170.75; G2: 921.90; G3: 830.30); HCHO (cumulative 0.99; range 0.01-9.81; G1: 1.91; G2: 0.14; G3: 0.02); PM10 (cumulative 207.37; range 0.37-1617; G1: 320.03; G2: 43.44; G3: 145.97; Table 6). However, PM2.5 was acceptable in most groups. Particle size $>0.3 \mu \mathrm{m},>1.0 \mu \mathrm{m},>2.5 \mu \mathrm{m},>5.0 \mu \mathrm{m}$, and $>10 \mu \mathrm{m}$ were 
high. The 95\% confidence interval of individual sample mean G1 (12.1016-20.5184), G2 (7.8580-11.442), G3 (4.5519-7.7880) is also depictive of calculated significant p-value (0.001365). The $95 \%$ confidence interval assuming equal variance for G1 (13.17-19.44), G2 (4.20-15.09), G3 (0.72-11.61) has F-statistics of value 9.9695 (Table 7). The significance of inter group difference of the mean is observed as: (G1 vs G2: $p=0.03$ ); (G1 vs G3: p=0.002); (G2 vs G3: p=0.003) (Table 3).

\begin{tabular}{|c|c|c|c|c|c|c|c|}
\hline $\begin{array}{l}\text { TI } \\
\text { groups }\end{array}$ & $\begin{array}{l}\text { Sample size } \\
(n=20)\end{array}$ & $\begin{array}{l}\text { Mean + } \\
\text { SD }\end{array}$ & SE & $\begin{array}{l}95 \% \mathrm{Cl} \text { of the individual sample } \\
\text { mean }\end{array}$ & $\begin{array}{l}95 \% \mathrm{Cl} \text { assuming equal } \\
\text { variance }\end{array}$ & $\begin{array}{l}\text { F- } \\
\text { statistics }\end{array}$ & p-value \\
\hline G1 & 10 & $\begin{array}{l}16.31+ \\
5.88\end{array}$ & 02.11 & $12.10-20.51$ & $13.17-19.44$ & \multirow{3}{*}{9.9695} & \multirow{3}{*}{0.001365} \\
\hline G2 & 05 & $\begin{array}{l}09.65+ \\
1.44\end{array}$ & 00.64 & $07.85-11.44$ & $4.20-15.09$ & & \\
\hline G3 & 05 & $\begin{array}{l}06.17+ \\
1.30\end{array}$ & 00.58 & $04.55-7.78$ & $0.72-11.61$ & & \\
\hline
\end{tabular}

TABLE 7: ANOVA of VLI for comparison within and among the groups $(n=20)$

ANOVA: analysis of variance, Cl: confidence interval, VLI: vehicle load index, SE: standard error.

\section{Intragroup correlation}

The intragroup Spearman's rank correlation coefficient is found to be significant in some groups (PM2.5 vs PM10: (G2: 0.03)]; PM1.0 vs PM2.5: (G2: 0.03)]. The intergroup Spearman's rank correlation coefficient was found significant for cumulated group TIs among some sites [VLI vs PM2.5 ( $r s=-0.43 ; \mathrm{p}=0.05$ ); PM2.5 vs PM10 ( $r s=0.49 ; \mathrm{p}=0.02$ ); PM1.0 vs PM10 ( $r \mathrm{~s}=0.71 ; \mathrm{p}=0.00$ ); PM1.0 vs PM2.5 ( $r s=0.59 ; \mathrm{p}=0.01$ ). The intergroup Spearman's rank correlation coefficient for cumulated group TIs among remaining sites was found nonsignificant for groups namely VLI vs PM10, PM10 vs TVOC, PM10 vs $\mathrm{CO}_{2}$ and PM10 vs HCHO (Table 3).

\section{Discussion}

Our study observed range of site mean for G3 (3.93-7.19), G2 (8.05-11.53), G1 (11.69-34.74) are consecutively ascending in nature similar to the observed DT (G3-6.08, G2-9.71, G1-19.03), night time (G3-6.27, G2 -9.60, G1-13.59), and overall group mean (G3-6.17, G2-9.65, G1-16.31) (Table 1). Similarly, a Madurai-based study 17 [9] has specifically underlined the importance of PM10 for vehicle-related pollution. The present study has also found highly increased PM10 in some of the TIs of G1, G2, and G3 groups [(G1/1: PM10, 1369.25); (G2/5: PM10, 113.25), and (G3/2: PM10, 600.65); Table 6). While this study assessed VLI also as an indicator of traffic intersection-wise pollution (Tables 1,2, and 7). Similarly, another study [10] conducted during February-March 2012 at Bhopal assessed PM10 and PM2.5 beyond permissible limits but $\mathrm{SO}_{2}$ and $\mathrm{NO}_{2}$ were within prescribed limits (AQI 105.54, February; AQI 105.89, March). However, the VLI was not assessed therein. The present study has been conducted at different locations of the city. However, the seasonal variation, large scales gatherings, and the annual increase in vehicular pollution due to the use of old vehicles may be limitations of the study.

The range of mean difference for PM10 was $7.2-12.7 \mu \mathrm{g} / \mathrm{m}^{3}$, whereas the mean difference for PM2.5 was 7.9 $\mu \mathrm{g} / \mathrm{m}^{3}$ in a study conducted by the Department of Air Quality at The Netherlands [11] indicating 1.3 times higher concentration than the background levels. This study observed group mean for PM10 in descending order among G1, G2, G3 (PM10: (G1: 319.87; G2: 138.00; G3: 51.37) and DT:NT for PM10 for the same order is noted as $2.50,0.09$, and 0.53 (Table 2). It hence shows that, despite the rainy season during the present study, the indicators of air pollution in the city of Bhopal are high as evidenced by high TVOC, $\mathrm{CO}_{2}, \mathrm{HCHO}$, and PM10 levels of cumulative datasets (Table 9), DT (Table 4), and NT (Table 5) for gaseous particles, particulate matter, and submicron particles assessed during June-September, 2019.

PM10 concentration was found to be raised due to local vehicular traffic in Finland in a study conducted by the Finnish Meteorological Institute [12], whereas PM2.5 concentration was assessed to be high at highwaysbased transport regions. The present study similarly infers that the increasing traffic load across traffic intersections in the city with expanding developmental initiatives under Capital Development Projects and other private developers shall pose further threats of higher air pollution levels in the years to come with seasonal variations challenging the public health scenario.

Seasonal trends of summer, autumn, winter were assessed in the Republic of Korea [13] by Korea Railroad Research Institute and found significantly high values of pollution indices viz. PM10 (42.5-108.4 $\left.\mu \mathrm{g} / \mathrm{m}^{3}\right)$, 
PM2.5 (61.1-64.0 $\left.\mu \mathrm{g} / \mathrm{m}^{3}\right)$, PM2.5/PM10(0.60), PM1.0(50.9- 52.2 $\left.\mu \mathrm{g} / \mathrm{m}^{3}\right)$, PM1/PM2.5 (0.79-0.85), and $\mathrm{CO}_{2}$ (686.9-701.5 ppm). These findings are in resonance with the findings of the present study. A study in Seoul Metropolitan Subway Stations at Han Yang University, Seoul [14] similarly found PM10 and PM2.5 to be higher than permissible levels of $150 \mu \mathrm{g} / \mathrm{m}^{3}$ and $35 \mu \mathrm{g} / \mathrm{m}^{3}$, respectively, which were significantly higher than those at ground level $(\mathrm{p}<0.05)$. These Korean studies highlight the need to generate evidence of air pollution by on-road vehicles and related adverse consequences on human health across the spectrum of demographic profiles. The University of Porto, Portugal [9] collected data of DT and NT for PM10, PM2.5, and PM1.0 and found these to be on a higher level with PM10 (DT mean $125+73 \mu \mathrm{g} / \mathrm{m}^{3}$; NT mean 110+71 $\mu \mathrm{g} / \mathrm{m}^{3}$ ), PM2.5 (DT mean $115+68 \mu \mathrm{g} / \mathrm{m}^{3}$; NT mean 108+70 $\mu \mathrm{g} / \mathrm{m}^{3}$ ), and PM1.0 (DT mean $114+68 \mu \mathrm{g} / \mathrm{m}^{3}$; NT mean 107+69 $\mu \mathrm{g} / \mathrm{m}^{3}$ ). Seasonal trends of summer, autumn, winter were assessed in the Republic of Korea [7] by Korea Railroad Research Institute and found significantly high values of pollution indices, viz., PM10 (42.5-108.4 $\left.\mu \mathrm{g} / \mathrm{m}^{3}\right)$, PM2.5 (61.1-64.0 $\mu \mathrm{g} / \mathrm{m}^{3}$ ), PM2.5/PM10 (0.60), PM1.0 (50.9- $52.2 \mu \mathrm{g} / \mathrm{m}^{3}$ ), PM1/PM2.5 (0.79-0.85), and $\mathrm{CO}_{2}$ (686.9-701.5 ppm). These findings are in resonance with the findings of the present study. These Korean studies highlight the need to generate evidence of air pollution by on-road vehicles and related adverse consequences on human health across the spectrum of demographic profiles. The University of Porto, Portugal [15] collected data of DT and NT for PM10, PM2.5, and PM1.0 and found these to be on a higher

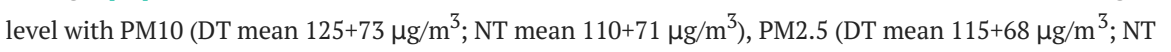
mean 108+70 $\mu \mathrm{g} / \mathrm{m}^{3}$ ), and PM1.0 (DT mean $114+68 \mu \mathrm{g} / \mathrm{m}^{3}$; NT mean 107+69 $\mu \mathrm{g} / \mathrm{m}^{3}$ ).

A study conducted at Central Road Research Institute, New Delhi [16] identified PM, VOC, and gas chemicals to be hazardous air pollutants in indoor and outdoor sources. As per sampling done by Grimm Dust Monitor and VOC Monitor at sampling time between 9:30 am and 5:00 pm while noting even the corridor air pollutants level to be alarming in office buildings (PM10: $83.4+44.7 \mu \mathrm{g} / \mathrm{m}^{3}$, PM2.5 65.0+37.3 $\mu \mathrm{g} / \mathrm{m}^{3}$, PM1.0 $\left.57.8+29.9 \mu \mathrm{g} / \mathrm{m}^{3}\right)$ and VOCs $(64.4+21.6 \mathrm{ppm})$. PM10 concentrations at schools located in city center, residential, and rural area with three classrooms in each (total nine measurement sites) observed PM10 during occupancy to be as (a) school 1: [site 1: (PM10 81.0+11.7 $\mu \mathrm{g} / \mathrm{m}^{3}$ ); site 2: PM10 104+63.5 $\mu \mathrm{g} / \mathrm{m}^{3}$ ); site 3:

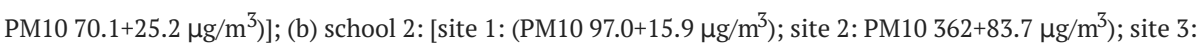

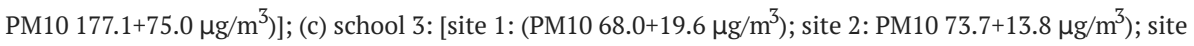
3: PM10 $\left.62.2+8.93 \mu \mathrm{g} / \mathrm{m}^{3}\right)$ ] were observed in a study [17]. A study conducted at Indian Institute of Technology, Kharagpur in association with West Bengal Pollution Control Board [18] assessed PM10 and PM2.5 at three sites in Kolkata and observed similar findings [PM2.5 site 1: $\left(96.31-355.19 \mu \mathrm{g} / \mathrm{m}^{3}\right)$; site 2: (116.29-363.63 $\left.\mu \mathrm{g} / \mathrm{m}^{3}\right)$; site 3: $\left(99.14-263.0 \mu \mathrm{g} / \mathrm{m}^{3}\right)$ PM10 site 1: $\left(140.5-471.7 \mu \mathrm{g} / \mathrm{m}^{3}\right)$; site 2: $(216.21-637.7$ $\left.\mu \mathrm{g} / \mathrm{m}^{3}\right)$; site 3: $\left.\left(185.42-487.07 \mu \mathrm{g} / \mathrm{m}^{3}\right)\right]$.

A study of PM1.0, PM2.5, and PM10 was conducted by Clean Air Commission of Vienna, Austria [19] at three urban [site 1: (PM1.0: 14.9+7.7; PM2.5 18.6+10.7; PM10 26.5+13.3); site 2: (PM1.0: $14.7+8.5$; PM2.5 18.8 +12.0; PM10 29.9+19.0; site 3: (PM1.0: 17.5+10.2; PM2.5 21.1+12.9; PM10 31.0+17.0], and one rural site 1: (PM1.0: 12.4+6.1; PM2.5 15.0+8.6; PM10 21.1+10.5) with observation of no seasonal influence at rural site. The present study focused on urban sites during one season only but higher levels of pollution were seen in traffic intersections under the classified categories (Tables 4 and 5). Contrastingly, the study of two Beijing sites, namely Chegongzhuang and Tsinghua, were assessed [20] for PM2.5 and found ranging between 37 and $357 \mu \mathrm{g} / \mathrm{m}^{3}$ and found PM2.5 to be highest in winter and lowest in summer. It is observed in an Australian study [21] that the concentration of particulate matter proportionately decreases for PM2.5 with increasing distance from road reaching to $40 \%$ of that level at $150 \mathrm{~m}$ distance.

A review report by Central Pollution Control Board, CPCB [22] has noted an average annual exposure level; of PM2.5 to be 34.39, 43.44, and 47 in the years 2000, 2005, 2010, 2011, and 2013, respectively. The present study has noticed PM2.5 vs PM10 (G2: p=0.03), PM1.0 vs PM2.5 (G2: p=0.03), and VLIs PM2.5 (G1+G2+G3: $\mathrm{p}=0.05)$.

In the present study, the ratio of DT and NT value assessments for VLI, TVOC, $\mathrm{CO}_{2}$, $\mathrm{HCHO}$, and PM10 shows higher proportion in DT for select values as per inter group variability [VLI (G1: 1.4; G2: 1.01); TVOC (G1:2.45; G3:3.66); $\mathrm{CO}_{2}$ (G1: 1.3; G2:1.19; G3:1.18); HCHO (G1: 2.69; G3: 03.00); PM10 (G1: 2.5); Table 2].

A study conducted in Italy [23] observed PM10 and PM2.5 at six sites of a town to be in the range of 41.5-89.5 $\mu \mathrm{g} / \mathrm{m}^{3}$ and $34.0-62.5 \mu \mathrm{g} / \mathrm{m}^{3}$ from the Advanced Research Project Agencies (ARPA) database. The present study results (Table 3) similarly show the same as Spearman's correlation coefficient for VLI vs PM2.5 $(\mathrm{p}=0.05)$, PM2.5 vs PM10 ( $\mathrm{p}=0.02$ ), PM1.O vs PM10 ( $\mathrm{p}=0.00$ ), and PM1.0 vs PM2.5 ( $\mathrm{p}=0.01)$ like the seasonal trends of particulate matter from heterogeneous traffic near urban roads assessed at IIT Madras [24] to be higher especially for PM10 concentration as per stated norms of World Health Organization $\left(50 \mu \mathrm{g} / \mathrm{m}^{3}\right)$ and Indian National Ambient Air Quality Standard (NAAQS; $100 \mu \mathrm{g} / \mathrm{m}^{3} ; 2010$ ). The Spearman correlation coefficient (PM10 vs PM2.5; 0.75; PM2.5 vs PM1.0; 0.92, PM2.5-10 vs PM1.0:0.11) was also assessed in a study by National Public Health Institute, Finland [25]. PM2.5 was also found raised as compared to the 
World Health Organization $\left(25 \mu \mathrm{g} / \mathrm{m}^{3}\right)$ and Indian NAAQS $\left(60 \mu \mathrm{g} / \mathrm{m}^{3}\right)$ during three fourth of the time. The post-monsoon season (PM10:189, PM2.5:84, PM1.0:66 $\mu \mathrm{g} / \mathrm{m}^{3}$, winter season (PM10:1135, PM2.5:73, PM1.59 $\mu \mathrm{g} / \mathrm{m}^{3}$, summer season (PM10:102, PM2.5:50, PM1.34 $\mu \mathrm{g} / \mathrm{m}^{3}$ ). A Netherland-based study [26] concluded black smoke and $\mathrm{NO}_{2}$ concentration to higher near motorways. A study conducted at the University of Dhaka

[3] observed mean PM1.0, PM2.5, and PM10 concentration to be 46.1+13.4, 76.0+16.2, 203.9+44.8 $\mu \mathrm{g} / \mathrm{m}^{3}$, whereas $\mathrm{NO}_{2}$ and TVOC were $0.076+0.007 \mathrm{ppm}$ and $90.0+46.0 \mathrm{ppm}$ in even indoor environment.

A sampling at six locations was conducted for Air Quality Indexing in Bangalore city [27] with AQI ranging 42.64-140.52 (unhealthy for the sensitive group), while noting the parameters like temperature, relative humidity, wind speed, and rainfall. In the present study, the ratio of DT and NT value assessments for VLI, TVOC, $\mathrm{CO}_{2}, \mathrm{HCHO}$, and PM10 shows a higher proportion in DT for select values as per intergroup variability [VLI (G1: 1.4; G2: 1.01); TVOC (G1: 2.45; G3: 3.66); $\mathrm{CO}_{2}$ (G1: 1.3; G2: 1.19; G3: 1.18); HCHO (G1: 2.69; G3: 03.00); PM10 (G1: 2.5); Table 2].

Another study conducted by Southern California Particle Center and Supersite of Centre for Occupational and Environmental Health, Los Angeles [28] measured temperature (Celsius) [summer: 30.3+3.7; winter 23.2+4.0], relative humidity (\%) [summer: 66.4+14.8; winter 43.1+21.4], wind speed (m/s) [summer: $1.36+0.66$; winter $1.27+0.67$ ], traffic density at 405 freeway (vehicles/min) [summer:231 +30 ; winter 236+27], traffic density at 710 freeway (vehicles/min) [summer: 203+12; winter 200+11]. The environmental conditions in the present study noted temperature, dew point, humidity wind pressure, wind speed, UV radiation and visibility also with predominantly high humidity (DT: $81.53 \%$, NT: $86.30 \%$ ), and low visibility (DT: 5.5 unit; NT: 4.85 units; Table 8).

\begin{tabular}{|c|c|c|c|c|c|c|c|}
\hline Particulars & Temperature (Celsius) & Dew point & Humidity (\%) & Wind pressure (Mb) & Wind speed $(\mathrm{Km} / \mathrm{H})$ & UV & Visibility (units) \\
\hline 01 & 26.15 & 24.35 & 81.35 & 1003 & 19.7 & Low & 5.50 \\
\hline NT & 25 & 24.2 & 86.3 & 1004 & 14.2 & Low & 4.85 \\
\hline
\end{tabular}

TABLE 8: Mean of various environmental parameters during DT and NT at included TIs under the study $(\mathrm{n}=20)$

DT: daytime, NT: nighttime, TI: traffic intersections.

\section{Conclusions}

The present study developed a new index namely VLI, which shall be more realistic to be adopted in the future for assessment of vehicular traffic concentration. The assessed increased levels of PM10, TVOC, $\mathrm{CO}_{2}$, and $\mathrm{HCHO}$ at all TIs under study including high, medium, and low traffic areas indicate moderate to severe public health threats to the resident community, commuters, nearby schools, and other people-centric facilities. These may lead to cough, asthma, bronchitis, stroke, and premature death among the exposed population as per their demographic and epidemiological profile. The presence of submicron particles $(>0.25$ $\mu \mathrm{m},>0.3 \mu \mathrm{m},>0.5 \mu \mathrm{m},>10 \mu \mathrm{m}$ ) in almost all sites of traffic intersections in DT and NT indicates public health threats due to deposition of these particles into alveoli leading to irreversible pulmonary damage. Hence, there is a felt need for comprehensive strategic pollution prevention and control policy-based initiatives for primary prevention-based public health interventions in varied geological settings, especially in developing nations.

\section{Additional Information \\ Disclosures}

Human subjects: All authors have confirmed that this study did not involve human participants or tissue. Animal subjects: All authors have confirmed that this study did not involve animal subjects or tissue. Conflicts of interest: In compliance with the ICMJE uniform disclosure form, all authors declare the following: Payment/services info: All authors have declared that no financial support was received from any organization for the submitted work. Financial relationships: All authors have declared that they have no financial relationships at present or within the previous three years with any organizations that might have an interest in the submitted work. Other relationships: All authors have declared that there are no other relationships or activities that could appear to have influenced the submitted work.

\section{References}

1. Kelly FJ, Fussell JC: Air pollution and public health: emerging hazards and improved understanding of risk . 
Environ Geochem Health. 2015, 37:631-649. 10.1007/s10653-015-9720-1

2. Air pollution in Delhi: an analysis. (2016). Accessed: October 24, 2020: http://cpcbenvis.nic.in/envis_newsletter/air\%20pollution\%20in\%20delhi.pdf.

3. Akther T, Ahmed M, Shohel M, Ferdousi FK, Salam A: Particulate matters and gaseous pollutants in indoor environment and Association of ultra-fine particulate matters (PM1) with lung function. Environ Sci Pollut Res Int. 2019, 26:5475-5484. 10.1007/s11356-018-4043-2

4. Hwang SH, Roh J, Park WM: Evaluation of PM10, CO2, airborne bacteria, TVOCs, and formaldehyde in facilities for susceptible populations in South Korea. Environ Pollut. 2018, 242:700-708. 10.1016/j.envpol.2018.07.013

5. El Sharkawy MF, Javed W: Study of indoor air quality level in various restaurants in Saudi Arabia . Environ Prog Sustainable Energy. 2018, 37:1713-1721. 10.1002/ep.12859

6. Amoatey P, Omidvarborna H, Baawain MS, Al-Mamun A: Indoor air pollution and exposure assessment of the gulf cooperation council countries: a critical review. Environ Int. 2018, 121:491-506. 10.1016/j.envint.2018.09.043

7. Gaur M, Bhandari K, Shukla A: Monitoring of total volatile organic compounds and particulate matter in an indoor environment. Curr Sci. 2018, 115:1787-1792. 10.18520/cs/v115/i9/1787-1792

8. Śmiełowska M, Marć M, Zabiegała B: Indoor air quality in public utility environments: a review . Environ Sci Pollut Res Int. 2017, 24:11166-11176. 10.1007/s11356-017-8567-7

9. Rajamanickam R, Nagan S: Assessment of air quality index for cities and major towns in Tamil Nadu, India . J Civil Environ Eng. 2018, 8:304. 10.4172/2165-784X.1000304

10. Gupta AD: Assessment of ambient air quality status and air quality index of Bhopal city (Madhya Pradesh), India. Int J Curr Sci. 2013, 9:96-101.

11. Janssen NA, Mansom DF, Jagt KV, Harssema H, Hoek G: Mass concentration and elemental composition of airborne particulate matter at street and background locations. Atmos Environ. 1997, 31:1185-1193. 10.1016/S1352-2310(96)00291-9

12. Pohjola MA, Kousa A, Kukkonen J, Härkönen J, Karppinen A, Aarnio P, Koskentalo T: The spatial and temporal variation of measured urban PM10 and PM2.5 in the Helsinki metropolitan area. Water Air Soil Pollution Focus. 2002, 2:189-201. 10.1023/A:1021379116579

13. Kwon SB, Jeong W, Park D, Kim KT, Cho KH: A multivariate study for characterizing particulate matter (PM(10), PM(2.5), and PM(1)) in Seoul metropolitan subway stations, Korea. J Hazard Mater. 2015, 2:295303. 10.1016/j.jhazmat.2015.05.015

14. Kim KY, Kim YS, Roh YM, Lee CM, Kim CN: Spatial distribution of particulate matter (PM10 and PM2.5) in Seoul Metropolitan Subway stations. J Hazard Mater. 2008, 154:440-443. 10.1016/j.jhazmat.2007.10.042

15. Madureira J, Paciência I, Fernandes Ede O: Levels and indoor-outdoor relationships of size specific particulate matter in naturally ventilated Portuguese schools. J Toxicol Environ Health A. 2012, 75:14231436. 10.1080/15287394.2012.721177

16. Gaur M, Singh R, Shukla A: Volatile organic compounds in India: concentration and sources . J Civil Environ Eng. 2016, 6:5. 10.4172/2165-784X.1000251

17. Alves C, Nunes T, Silva J, Duarte M: Comfort parameters and particulate matter (PM10 And PM2.5) in school classrooms and outdoor air. Aero Air Qual Res. 2012, 13:1521-1535. 10.4209/aaqr.2012.11.0321

18. Nag S, Gupta AK, Mukhopadhyay UK: Size distribution of atmospheric aerosols in Kolkata, India and the assessment of pulmonary deposition of particle mass. Indoor Built Environ. 2015, 14:381-389. 10.1177/1420326X05057949

19. Gomiščeka B, Haucka H, Stopper BS, Preining O: Spatial and temporal variations of PM1, PM2.5, PM10 and particle number concentration during the AUPHEP project. Atmos Environ. 2004, 38:3917-3934. 10.1016/j.atmosenv.2004.03.056

20. He K, Yanga F, Maa Y, et al.: The characteristics of PM2.5 in Beijing, China . Atmos Environ. 2001, 35:49594970. 10.1016/S1352-2310(01)00301-6

21. Hitchins J, Morawska L, Wol R, Gilbert D: Concentrations of submicrometre particles from vehicle emissions near a major road. Atmos Environ. 2000, 34:51-59. 10.1016/S1352-2310(99)00304-0

22. Gautam S, Yadav A, Tsai CJ, Kumar P: A review on recent progress in observations, sources, classification and regulations of PM2.5 in Asian environments. Environ Sci Pollut Res Int. 2016, 23:21165-21175. 10.1007/s11356-016-7515-2

23. Feretti D, Pedrazzan R, Elisabetta E, et al.: Risk is in the air: polycyclic aromatic hydrocarbons, metals and mutagenicity of atmospheric particulate matter in a town of Northern Italy. Mutat Res. 2019, 842:35-49. 10.1016/j.mrgentox.2018.11.002

24. Bathmanabhan S, Madanayak SN: Analysis and interpretation of particulate matter - PM10, PM2.5 and PM1 emissions from the heterogeneous traffic near an urban roadway. Atmos Pollut Res. 2010, 1:184-194. 10.5094/APR.2010.02

25. Penttinen P, Timonen KL, Tiittanen P, Mirme A, Ruuskanen J, Pekkanen J: Ultrafine particles in urban air and respiratory health among adult asthmatics. Eur Respir J. 2001, 17:428-435. 10.1183/09031936.01.17304280

26. Roorda-Knape MC, Janssen NA, de Hartog J, Van Vliet PH, Harssema H, Brunekreef B: Traffic related air pollution in city districts near motorways. Sci Total Environ. 1999, 235:339-341. 10.1016/S00489697(99)00217-X

27. Kamath K, Shappa L: Air quality indexing for selected areas in Bangalore City, Karnataka State, India . IJIRSET. 2004, 3:15625-15630. 10.15680/IJIRSET.2018.0712076

28. Zhu Y, Hinds WC, Shen S, Sioutas C: Seasonal trends of concentration and size distribution of ultrafine particles near major highways in Los Angeles. Aerosol Sci Technol. 2004, 38:5-13.

10.1080/02786820390229156 